\section{Beware alternate funding plans}

\section{To the editor:}

The introduction of salaried positions in community hospitals will change emergency medicine. Until recently, physicians practised autonomously under a fee-for-service (FFS) payment scheme. Now, for the sake of a shortterm pay raise, many physicians are jumping to alternate funding plans (AFPs). But under an AFP, group dynamics will change and independence will be lost.

Governments and hospital administrators will monitor productivity. Physicians below the standard will be singled out and, presumably, dealt with. Under FFS, hard-working physicians are rewarded, but under an AFP they will subsidize slower moving physicians - a situation that will lead to frustration and decreasing productivity. Within AFPs, money earned by individuals would be controlled by and directed to others. For example, groups could divert clinical funds to educational activities, whether or not all members of the group actually require or benefit from those activities. Under this scheme, harder-working physicians would fund a disproportionate amount of the cost. In the future, groups may decide to divert clinical funds to other activities, further eroding hard-earned incomes.

AFPs look like a sweet deal to some, but we should consider what is being offered and at what cost. Our government's main goal is to control costs, not to give emergency physicians a raise. AFP contracts rarely cover expenses for management and shadow billing, for additional coverage during busy pe- riods, or other group expenses. When family physicians see their patients in the ED these funds are subtracted from the ED's AFP income. In one Ontario centre, this factor reduced payments to emergency physicians by $\$ 300000$ within a $\$ 1.2$ million contract and led to a much lower pay rate than specified in the AFP contract.

The group economics associated with AFPs raise other difficult issues. Should all in the emergency medicine group have equal voting power regardless of hours worked, patients seen or income generated? What are the penalties for tardiness, long lunch breaks and poor productivity? Should people with different skills, experience and work ethics be paid equally? Will AFPs kill motivation and make physicians regress toward the lowest common denominator?

Let's look before we leap.

\section{Thomas Marshall, MD}

Peterborough Regional Hospital

Peterborough, Ont.

thomas.marshall@sympatico.ca

\section{Emergency physicians and death certificates}

\section{To the editor:}

I was disturbed by the authors' response' $^{1}$ to Dr. Jim Gall's letter ${ }^{2}$ regarding their article. ${ }^{3}$ The authors acknowledge that they work in an institution "that routinely contacts the coroner for all ED pronouncements." They further admit that this practice was not changed despite efforts by the regional coroner's office to emphasize "the need for emergency physicians to complete the death certificate and to call the coroner's office only when the death met certain criteria." This request is de- scribed as "adding responsibility and more paperwork" and "must be weighed against competing service and academic demands."

Ontario, like most jurisdictions, has a statutory obligation to report certain deaths, such as those that are the result of trauma or medical misadventure. In the absence of the statutory criteria, it is every attending physician's obligation to complete the death certificate and attendant institution paperwork. Indeed, our duty to our patient is not ended until the death routines (e.g., notifying relatives, completing paperwork) have been performed. We are all busy, but deaths are infrequent and important events, and our obligations should not be taken lightly. In a teaching institution, in which future trainees are looking for role models and forming habits, the completion of our statutory and moral obligations should be completed faithfully and without reluctance or regret.

\section{Howard Ovens, MD \\ Director \\ Schwartz/Reisman Emergency Centre \\ Mount Sinai Hospital \\ Toronto, Ont.}

\section{References}

1. Cheung M, Morrison L, Verbeek PR. Prehospital vs. ED pronouncement of death [letter]. CJEM 2001;3(3):177-81.

2. Gall J. Prehospital vs. ED pronouncement of death [letter]. CJEM 2001;3(3):177.

3. Cheung M, Morrison L, Verbeek PR. Prehospital vs. emergency department pronouncement of death: a cost analysis. CJEM 2001;3(1):19-25.

\section{[The authors respond:]}

Dr. Ovens reminds us to strive to live up to the responsibilities of a complete physician against the adversity of the hectic climate in which we work. To do 